\title{
遺伝的アルゴリズムを用いたアレーアンテナの 非対称の等サイドローブ指向性制御†
}

\author{
大久保 茂 ${ }^{* 1}$ 南山 文一 $* 2$
}

\begin{abstract}
アレーアンテナの指向性において，メインビームの方向に対して非対称の等サイドローブ指向性を得る 手法は複数提案されているが, それらの手法はテイラー分布を用いた手法であり，他の指向性への適用範 囲が狭いことが挙げられている。本論文では，アンテナの指向性に扔いて指定した方向で設定したレべル をとるレベル制御と, 設定した方向でサイドローブレベルが極值となるサイドローブ制御の給電振幅と移 相量が同時に等しくなるとき, 非対称の等サイドローブ指向性が理論的に得られると考え, アレーアンテ ナのアンテナ素子への給電振幅, 移相量を制御して非対称にサイドローブレベルが等しい指向性（非対称 の等サイドローブ指向性）の手法を提案している。本手法では。このレベル制御とサイドローブ制御を用 いた本手法は, 複雑な手順を要せず, 他の指向性制御にも適用が可能である。本論文ではアレーアンテナ の中心に対して各アンテナ素子への給電振幅は対称に, 移相量は逆位相にして理論式の簡略化を行い, さ らに計算時間の短縮を図るために，最適化法の一つである遺伝的アルゴリズム（GA）を用いている. キーワード：アレーアンテナ, 非対称の等サイドローブ指向性, 遺伝的アルゴリズム, レベル制御, サイドローブ制御
\end{abstract}

\section{1 . はじめに}

携帯電話の契約件数は 1 億件を超え，もはや国民一 人にほぼ一台となり, 携帯電話をはじめとする無線通 信は現代社会において我々の生活になくてはならない 存在になっている。無線通信において，電波の送受信 を行っているのがアンテナであり, 重要な役割を担っ ている。そのアンテナに扎いて電磁波が不必要な方向 へ放出されることは，単にエネルギーの損失だけでは なく，電磁污染として他の通信系に影響を与える可能 性がある。そのため，アンテナの放射パターンは，所 望の指向性を得ることが求められる。その中でも指向 性が容易に制御できるアンテナとしてアレーアンテナ がある.アレーアンテナの特長としては，アンテナ素 子の種類, 配列方法などによって単一のアンテナで実 現できない新たな機能を付加することができる。特に アンテナに要求される指向性をその要求に応じて満た すような最適化の方法が指向性制御とよばれ，アレー アンテナの持つ最も大きな機能の一つである．指向性 制御によってメインビーム幅 $[1]$, サイドローブの抑

$\dagger$ Controlling Asymmetric Equal Side Lobe Level in Radiation Patterns of Array Antenna using Genetic Algorithm Shigeru OKUBO and Fumikazu MINAMIYAMA

* 1 福井工業高等専門学校

Fukui National College of Technology

* 2 名古屋大学工学研究科

Graduate School of Engineering, Nagoya University
圧, そのレベル制御 [2], 零点 (ヌル点)の位置 $[3]$ およ び利得などが制御できる。アレーアンテナの代表的な 指向性にはサイドローブがすべて等しくなる指向性 (等サイドローブ指向性) がある。この指向性を得るド ルフ・チェビシェフ法 [4]では, 給電振幅のみを変化 させている。しかし, アレーアンテナは給電振幅だけ でなく, 移相量も変化させることでメインビームに対 して非対称の指向性を得ることができる. 非対称の等 サイドローブ指向性を得る手法は複数提案 $[5]$ ～[8]さ れているが，それらの手法は，テイラー分布 [9]を用 いた手法であり，他の指向性への適用範囲が狭いこと が挙げられる。

本論文では，アレーアンテナにおけるアンテナ素子 への給電振幅, 移相量を同時に制御してメインビーム 方向に対して非対称にサイドローブレベルが等しい指 向性(非対称の等サイドローブ指向性)の手法を提案し ている. 本手法は指定した方向で設定したレベルをと るレベル制御と, 設定した方向でサイドローブレベル が極值となるサイドローブ制御の給電振幅と移相量が 同時に等しくなるとき, 非対称の等サイドローブ指向 性が理論的に得られる。本論文では, 非対称の等サイ ドローブ指向性の計算の例を示し, 本手法の有効性を 明らかにしている。 また，アレーアンテナの中心に対 して各アンテナ素子への給電振幅は対称に, 移相量は 逆位相にして理論式の簡略化を行い, さらに計算時間 の短縮を罒るために, 最適化法の一つである遺伝的ア 
ルゴリズム $(\mathrm{GA})[10]$ を用いている.

\section{2. アレーアンテナ}

\section{（1） アレーアンテナの概要}

アレーアンテナとは複数のアンテナ素子を一直線に 配置したものである。図 1 に $N$ 本のアンテナ素子で構 成されるアレーアンテナを示す，アンテナ素子はすべ て等方性で, アンテナ素子は一定間隔 $d$ で配置されて いるものとする.図 1 はアンテナ素子数が偶数の場合 を示している。ただし，アンテナ素子に給電する振幅 を $A_{n}$, 移相量を $\delta_{n}$, 距離を $r$, 方向を $\theta, m=N / 2$ で ある。

\section{（2） アレーアンテナの指向性の一般式}

図 1 のアンテナ素子偶数本のアレーアンテナの指向 性 $A F_{N}(\theta)$ (Array Factor) は次のように表される.

$A F_{N}(\theta)=\sum_{n=1}^{m} A_{n} \cos \left(\delta_{n}+\frac{2 n-1}{2} k d \cos \theta\right)$

ただし， $\lambda$ は波長， $k=(2 \pi / \lambda)$ は伝搬定数とする. ここでは, アレーアンテナの中心に対して給電振幅は 上下対称, 移相量は逆位相に設定している。これは移 相量を逆位相に設定していることで $A F_{N}(\theta)$ が実数に なるため，理論式の簡略化を図っている。さらに， $d=$ $\lambda / 2$ とすると, $k d \cos \theta=\pi \cos \theta$ となり,$\psi=\pi \cos \theta$ と なる。ただし, $A F_{\text {max }}$ は $A F_{N}(\theta)$ の最大値.

$$
\begin{aligned}
& A F_{N}(\theta)=\sum_{n=1}^{m} A_{n} \cos \left(\delta_{n}+\frac{2 n-1}{2} \psi\right) \\
& A F(\theta)=20 \log \frac{\left|A F_{N}(\theta)\right|}{\left|A F_{\max }\right|}
\end{aligned}
$$

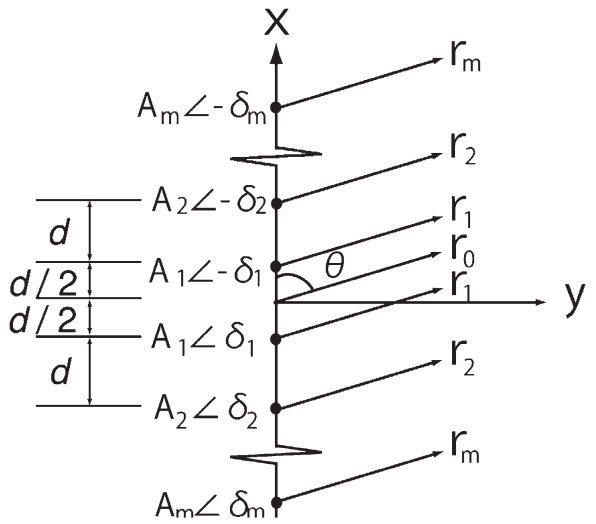

図 1 アレーアンテナ

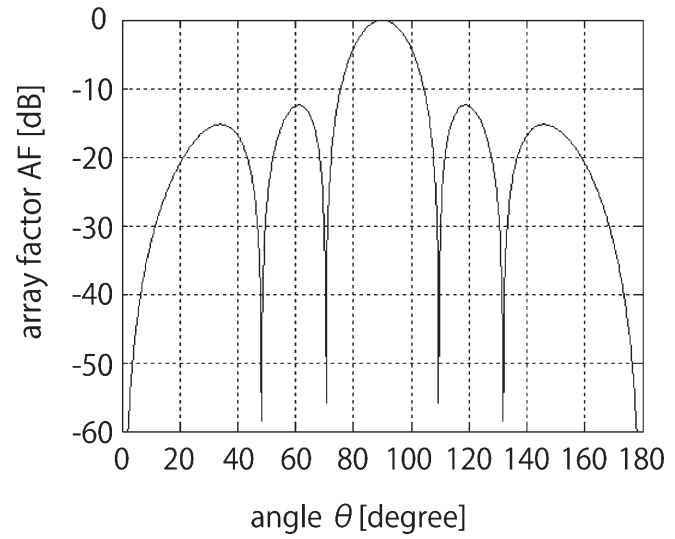

図 2 アレーアンテナの指向性 $(N=6)$

\section{（3） アレーアンテナの指向性}

アレーアンテナの指向性は式 (2) で表される。アン テナ素子 6 本, 給電振幅 $A_{n}=\left[A_{1}, A_{2}, A_{3}\right]=[1,1,1]$, 移相量 $\delta_{n}=\left[\delta_{1}, \delta_{2}, \delta_{3}\right]=[0,0,0]$ を式 (2)に与え た場合，式(4)になり，図 2 にその指向性を示す.

$$
\begin{aligned}
A F_{6}(\theta)=1 \times \cos \left(0+\frac{1}{2} \psi\right)+ & 1 \times \cos \left(0+\frac{3}{2} \psi\right) \\
& +1 \times \cos \left(0+\frac{5}{2} \psi\right)
\end{aligned}
$$

\section{3 、レベル制御}

レベル制御とは任意に指定した方向のレベルを，設 定した值にする制御である，本論文においては，給電 振幅, 移相量も変化させる。皇して, このレベル制御 の給電振幅 $A_{l n}$, 移相量 $\delta_{l n}$ を求める一般式は次のよう に表すことができる。まず，

$\frac{\left|A F_{N}(\theta)\right|}{\left|A F_{\max }\right|}=h$

とすると，式(3)は次のように表される。ただし，設 定レベルを $D[\mathrm{~dB}]$ とする

$D=A F(\theta)=20 \log (h)$

ここで，解となる給電振幅，移相量を求めるために指 向性の一般式を変形する。ただし， $\psi_{l}=\pi \cos \theta_{l}, \theta_{l}$ は レベル制御の指定方向.

$A F_{N}(\theta)=\sum_{n=1}^{m} A_{l_{n}}\left\{\cos \delta_{l n} \cos \left(\frac{2 n-1}{2} \psi_{l}\right)-\sin \delta_{l n} \sin \left(\frac{2 n-1}{2} \psi_{l}\right)\right\}$

指向性の式 (3)に打ける $A F_{\text {max }}$ は方向 $\theta$ がメインビーム 方向 $\theta_{\max }, \psi_{\max }=\pi \cos \theta_{\max }$ であるため, 式(7) は次のよ うに表される。 


$$
\begin{aligned}
A F_{\max } & =A F_{N}\left(\psi_{\max }\right) \\
& =\sum_{n=1}^{m} A_{l_{n}}\left\{\cos \delta_{l_{n}} \cos \left(\frac{2 n-1}{2} \psi_{\max }\right)-\sin \delta_{l_{n}} \sin \left(\frac{2 n-1}{2} \psi_{\max }\right)\right\}
\end{aligned}
$$

式(5)に式(7)と式(8)を代入し，まとめると次のよう になる.ただし, $D$ は設定レベル, $h$ は式(6)により ${ }_{h=10}{ }^{D} / 20$, $m$ 番目のアンテナ素子を基準とするため, $A_{l m}=1$, $\delta_{l m}=0$ とする.

$$
\begin{aligned}
h \cos & \left(\frac{2 m-1}{2} \psi_{\max }\right)-\cos \left(\frac{2 m-1}{2} \psi_{l}\right) \\
= & \sum_{n=1}^{m-1} A_{l_{n}}\left[\left\{\cos \delta_{l_{n}} \cos \left(\frac{2 n-1}{2} \psi_{l}\right)-\sin \delta_{l_{n}} \sin \left(\frac{2 n-1}{2} \psi_{l}\right)\right\}\right. \\
& \left.-h\left\{\cos \delta_{l_{n}} \cos \left(\frac{2 n-1}{2} \psi_{\text {max }}\right)-\sin \delta_{l_{n}} \sin \left(\frac{2 n-1}{2} \psi_{\text {max }}\right)\right\}\right]
\end{aligned}
$$

レベル制御の解である給電振幅 $A_{l n}$, 移相量 $\delta_{l n}$ を求め る一般式は次のようになる。ここで, $A_{l n} \cos \delta_{l n}=A_{a n}$, $A_{l n} \sin \delta_{l n}=A_{b n}$ とおく.

$$
\begin{aligned}
h \cos \left(\frac{2 m-1}{2} \psi_{\max }\right)-\cos \left(\frac{2 m-1}{2} \psi_{l}\right) \\
=\sum_{n=1}^{m-1}\left[A_{a n}\left\{\cos \left(\frac{2 n-1}{2} \psi_{l}\right)-h \cos \left(\frac{2 n-1}{2} \psi_{\max }\right)\right\}\right. \\
\left.\quad-A_{b n}\left\{\sin \left(\frac{2 n-1}{2} \psi_{l}\right)-h \sin \left(\frac{2 n-1}{2} \psi_{\max }\right)\right\}\right]
\end{aligned}
$$

以上より, アレーアンテナの給電振幅 $A_{l n}$, 移相量 $\delta_{l n}$ が式(10)を満たすことによって，レベル制御された指 向性を得ることができる。

\section{4. サイドローブ制御}

サイドローブ制御とは任意に指定した指向性の方向 でサイドローブが極值をとる制御である。このサイド ローブ制御の給電振幅 $A_{s n}$, 移相量 $\delta_{s n}$ を求める一般式 は, 指向性の式 (2) を $\theta$ で微分し, 極值を求めるため に $A F^{\prime}{ }_{N}(\theta)=0$ とする。それをまとめたのが式(11)で ある。ただし $\psi_{s}=\pi \cos \theta_{s}, \theta_{s}$ は指定方向である.

$A F_{N}^{\prime}(\theta)=\left[-\sum_{n=1}^{m} A_{s n} \frac{2 n-1}{2}\left\{\sin \delta_{s n} \cos \left(\frac{2 n-1}{2} \psi_{s}\right)+\cos \delta_{s n} \sin \left(\frac{2 n-1}{2} \psi_{s}\right)\right\}\right] \pi \sin \theta$

$\sin \theta$ は $\theta=0^{\circ}, 180^{\circ}$ において 0 を満たす. 次に, 式(11) における括弧の中について考える。ここで $A_{s m}=1$ ， $\delta_{s m}=0, A_{s n} \sin \delta_{s n}=A_{s a n}, A_{s n} \cos \delta_{s n}=A_{s b n}$ とすると, サイドローブ制御の一般式は次のように示される.

$-(2 m-1) \sin \left(\frac{2 m-1}{2} \psi_{s}\right)=\sum_{n=1}^{m-1}(2 n-1)\left\{A_{s a n} \cos \left(\frac{2 n-1}{2} \psi_{s}\right)+A_{s b n} \sin \left(\frac{2 n-1}{2} \psi_{s}\right)\right\}$

以上よりアレーアンテナの給電振幅 $A_{s n}$, 移相量 $\delta_{s n}$ が
式(12)を満たすことによって, サイドローブ制御指向 性を得ることができる。

\section{5 . 非対称の等サイドローブ指向性}

（1）レベル制御とサイドローブ制御の組み合わせ

アレーアンテナの代表的な指向性にはサイドローブ のピークがすべて等しくなる指向性(等サイドローブ 指向性) がある。この指向性の応用例として, メイン ビームに対して非対称の指向性である非対称の等サイ ドローブ指向性がある. 従来の研究における手法[5] [8]は，テイラー分布 $[9]$ を基本とし，所望のサイド ローブレベルを満たすよう理論式の展開を行って, 実 現される.テイラー分布は高利得, 低サイドローブと いう利点を持つためサイドローブを抑圧された指向 性を得る手法としてアンテナの設計によく用いられて きた。しかし，テイラー分布を用いる手法では低サイ ドローブを実現することを目的としているため，サイ ドローブレベルのミニマムレベルを制御することは考 慮されておらず, 得られる指向性が限定され, 適用範 囲が狭いという問題点が挙げられる。

本論文に打ける提案手法に扎いて，等サイドローブ 指向性は各サイドローブのピーク方向のレベルが等し くすることにより実現できる。そのため, サイドロー ブのピーク方向はサイドローブ制御で, サイドローブ のレベルを等しくするのはレべル制御で行なえば，等 サイドローブ指向性制御が可能である。また，レベル 制御においては，それぞれの指定方向において異なる 設定レベルを与えることが可能である。これらを用い れば，メインビーム方向に対して右側と左側で異なる 設定レベルを与えることにより，非対称の等サイド ローブ指向性が求められる。

\section{（2）非対称の等サイドローブ指向性計算例}

ここで, 非対称の等サイドローブ制御の計算例を示 す. アンテナ素子数 $N=10$ 本とし, 設定レベル $D=$ $-30 \mathrm{~dB}$ (メインビームの右側)， $-40 \mathrm{~dB}$ (左側)とする非 対称の等サイドローブ指向性について計算する。この とき, 指向性の左右両側で 2 つ上上サイドローブが 現れるようにするため, アンテナ素子数は10本とす る.この場合, レベル制御の指定方向数は 8 つ $\left(\theta_{l n}=\right.$ $\left.\left[\theta_{l 1} \sim \theta_{l 8}\right]\right)$, サイドローブ制御の指定方向数は 8 つ $\left(\theta_{s n}=\left[\theta_{s 1} \sim \theta_{s 8}\right]\right)$ 存在する.式 (10) および式 (12) か ら求められる給電振幅 $A_{l n}=\left[A_{l 1} \sim A_{l 4}\right]$ および $A_{s n}=[$ $\left.A_{s 1} \sim A_{s 4}\right]$, 移相量 $\delta_{l n}=\left[\delta_{l 1} \sim \delta_{l 4}\right]$ および $\delta_{s n}=\left[\delta_{s 1} \sim\right.$ $\left.\delta_{l 4}\right]$ が, 同じになるようなこれら 8 個の指定方向に任 意の数值を逐次代入して非対称の等サイドローブ指向 性の給電振幅 $A_{e l}$, 移相量 $\delta_{e l}$ を計算した (逐次法). 逐 


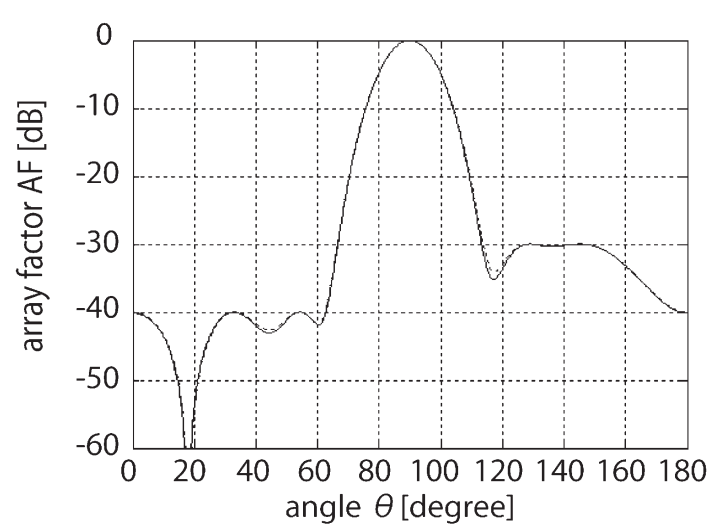

図 3 非対称の等サイドローブ指向性 $(N=10)$ — 逐次法 GA

次法とは, 解空間を全探索しており, レベル制御, サ イドローブ制御の理論式へ代入する指定方向 $\left(\theta_{l n}, \theta_{s n}\right)$ を刻及幅 $0.01^{\circ}$ で逐次変化させて, 解探索を行ってい る。その結果,

$\theta_{l n}=\left[32.89^{\circ}, 53.90^{\circ}, 54.31^{\circ}, 62.73^{\circ}, 113.27^{\circ}\right.$, $\left.128.73^{\circ}, 129.26^{\circ}, 145.34^{\circ}\right]$

$\theta_{s n}=\left[32.89^{\circ}, 44.39^{\circ}, 54.31^{\circ}, 60.36^{\circ}, 117.04^{\circ}\right.$, $\left.129.26^{\circ}, 136.47^{\circ}, 145.34^{\circ}\right]$

$$
A_{e l}=[14.8452,10.9731,7.3482,3.2176,1.0]
$$$$
\delta_{e l}=[0.0195,-0.0272,-0.0369,-0.0179,0]
$$

となった。この給電振幅, 移相量を式(2)に代入した ときの指向性を図 3 の実線で示す。設定レベルどおり の非対称の等サイドローブ指向性になっている。 サイ ドローブ制御の指定方向でそれぞれサイドローブが極 值をとり，レべル制御の指定方向でサイドローブレベ ルが設定レベルとなっている。また， サイドローブの ピークとなる方向でサイドローブ制御とレベル制御の 指定方向になっていることがわかる。このことから， サイドローブ制御でサイドローブのピークの方向を制 御し, レベル制御でサイドローブのピークのレベルを 制御している。しかし, 全ての組み合わせを比較し計 算する逐次法を用いて計算を行なっており，計算時間 が約12時間を要した。このシミュレーション環境とし ては,コンピュータはIntel 社のCPU, Celeronを搭 載し, $\mathrm{CPU}$ クック周波数が $1.3 \mathrm{GHz}$ のものを用い た．計算機の性能が計算時間に影響するが，このよう に逐次法を用いると計算が長時間になった。

\section{6. 遺伝的アルゴリズム（GA）を用いた 非対称の等サイドローブ指向性}

前章で行った逐次法を用いて非対称の等サイドロー ブ指向性を求める手法は, 全ての組み合わせについて
計算するため, 計算量が多く, 計算時間が膨大とな る.このことでアンテナ素子数が増加すると, 計算量 は指数関数的に増加してしまう。この問題点を解決す るため, 計算過程に打いて最適化法の一つの遺伝的ア ルゴリズム(Genetic Algorithm, 以下, GAと省略)を 適用した。この探索問題においては複雑な評価関数の 形状であるため，局所的な解に陥ることがある。その ため, GAにおいては, 突然変異といったプロセスに おいて局所的な解に陥ることを阻止している。また， GAは，並列探索を行っており，実用時間内で十分な 精度の解を得られるという特徵を有しているため, 今 回はGAを採用した。また, 本論文において適用した GAの手法は, 基本的な手順を基にしている「シンプル

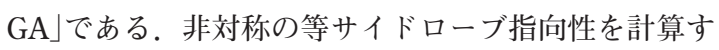
る時の指定方向 $\theta$ を遺伝子と見立て 8 ビットで表し, $N=10$ の場合は指定方向がレベル制御, サイドローブ 制御ともに 8 つであるので合計16個の遺伝子で染色体 を構成する。探索開始時の遺伝子初期值の生成には, ランダムに発生させている。個体群の大きさは 8 個の 染色体とする. 評価関数は, 設定レベルと各サイド ローブの最大值との差とする. 個体群の染色体ごとに 評価值を算出し, 值の小さい順にランク付けして下位 4 つを劣勢染色体として削除する。そして, 遺伝子の 中心の 1 点で分割し，4つの優秀染色体同士から新た な次の世代の 4 つの染色体を生成する一点交叉を行 う. 例えば 1 番目の優秀染色体の前半部分, 2 番目の 後半部分を組み合わせて新たな染色体が生成される。 4 つの優秀染色体は淘汰, 保存する.よって, 元の大 きさである合計 8 つ次世代の個体群を再構築し, こ の操作を繰り返し行う。この遺伝子を組み替える操作 がGAに打ける「交叉」という手順である。このときの GAのパラメータを表 1 に示す. GAによって得られた

表 1 GAのパラメータ

\begin{tabular}{|c|c|}
\hline \hline 個体群の大きさ & 8 個 \\
\hline 遺伝子の長さ & $8 \mathrm{bit}$ \\
\hline 染色体の長さ & $8 * 16=128 \mathrm{bit}(N=10)$ \\
\hline ループ回数 & 200 回 \\
\hline 突然変異の発生 & $5 \%$ \\
\hline \hline
\end{tabular}

表 2 計算結果 $(N=10)$

\begin{tabular}{|l|l|l|l|l|l|}
\hline \hline 設定レベル[dB] & \multicolumn{3}{|c|}{-40} & \multicolumn{2}{|c|}{-30} \\
\hline ピーク方向[○ ] & 0 & 34.02 & 47.52 & 122.22 & 142.74 \\
\hline $\begin{array}{l}\text { 設定レベルとの } \\
\text { 誤差[dB] }\end{array}$ & 0.0034 & 0.0046 & 0.0059 & 0.0024 & 0.0041 \\
\hline \hline
\end{tabular}




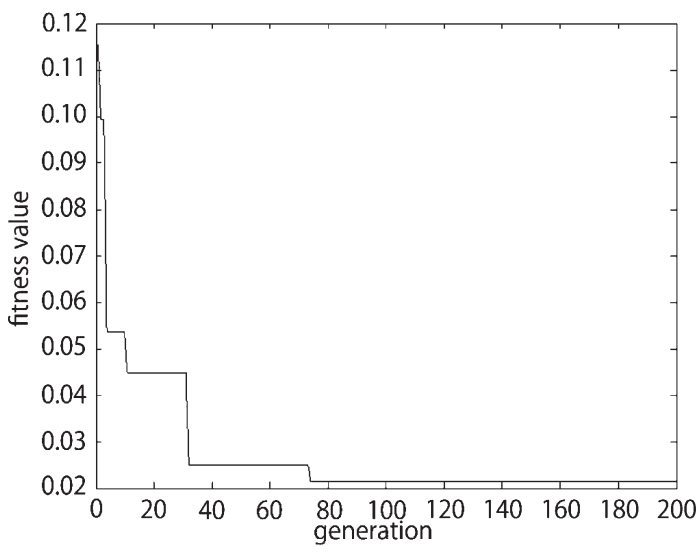

図 4 適合曲線 $(\mathrm{GA})$

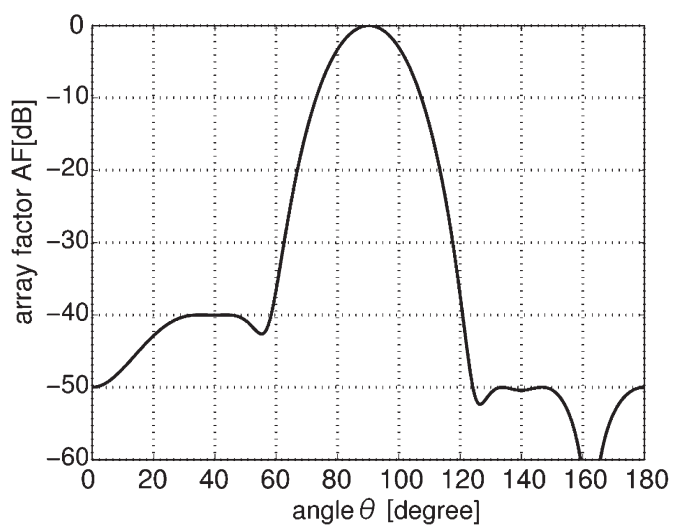

図 5 非対称の等サイドローブ指向性 $(N=12)$

給電振幅と移相量は $A_{e l}=[14.8466,10.9640,7.3322$, $3.2106,1], \delta_{e l}=[0.0195,-0.0272,-0.0369$, $-0.0179 ， 0]$ であ. GAによって得られた指向性を眓 3 における破線，各サイドローブの最大值のレベルと設 定レベルとの䛊差を表 2 に示す。罒 3 では $45^{\circ}, 115^{\circ}$ の極小付近で差異がある。表 2 からもわかるように設 定レベルとの誤差は最大で $0.0059 \mathrm{~dB}$ とっている.

GAの評価值の収束状況を図 4 に示すが, 解が第200世 代で収束していると判断すると，計算にかかった時間 はGAの場合約 250 秒で, 逐次法と比べ約 170 分の 1 に 短縮されている。以上のことから，本手法において計 算時間および解の精度を総合的に判断して，GAを用 いた場合でも妥当な解を得られる. 前章で示した逐次 法を用いると，アレーアンテナの素子数が増加すれ ば，計算量が増加する。実用的なアレーアンテナにお いては, 数本のアンテナから100本を越えるような素 子数を用いる場合も存在する。そのため，アンテナ素 子数に対して汎用的に適用させるためにも，GAを用 いた最適化は必要となる。本論文で取り上げているの

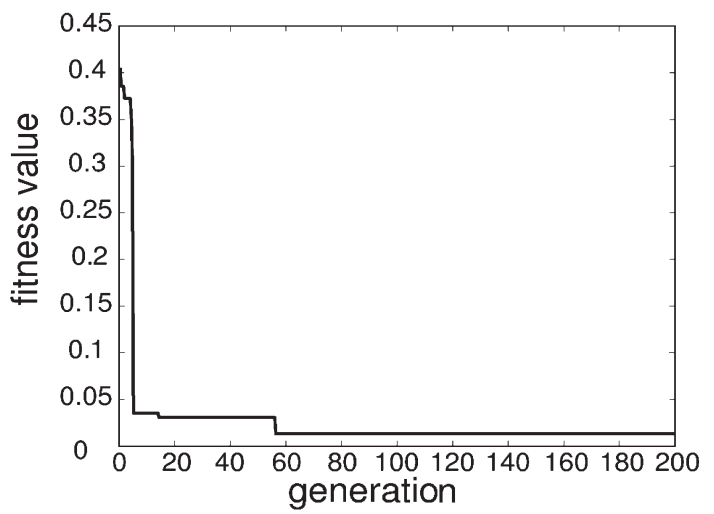

図 6 適合曲線 (GA)

表 3 計算結果 $(N=12)$

\begin{tabular}{|l|l|l|l|l|l|}
\hline 設定レベル[dB] & \multicolumn{2}{|c|}{-40} & \multicolumn{3}{c|}{-50} \\
\hline ピーク方向[○ $]$ & 35.46 & 43.92 & 133.92 & 146.88 & 180 \\
\hline $\begin{array}{l}\text { 設定レベルとの } \\
\text { 誤差[dB] }\end{array}$ & 0.0045 & 0.0015 & 0.0010 & 0.0043 & 0.0017 \\
\hline
\end{tabular}

は 8 本である。これはアンテナ素子数が多すぎれば, 特性が見えにくくなり, 逆に, 本数を少なくし, 簡単 化しすぎれば，解空間も狭く，結果の信頼性に欠ける と考えられるためである。つまり，GAを適用するこ とで実用時間内に解を得られることが可能である。

同様にアンテナ素子数を増加させた場合 $(N=12)$ も 行った. 設定レベルは $D=-50 \mathrm{~dB}$ (メインビームの右 側), $-40 \mathrm{~dB}$ (左側)としている。攵の結果, 給電振幅, 移相量は $A_{n}=[85.47,57.09,24.81,3.89,1.64$, $1.00], \delta_{n}=[-3.14,-3.11,-3.07,-2.92,-0.14,0.00]$ となった。この指向性を図 5 に示す。この場合の GA の収束状況を図 6 に, 各サイドローブの最大值のレベ ルと設定レベルとの誤差を表 3 に示す. 図 6 の収束状 況より200世代で収束している判断すると, 計算にか かった時間は約 260 秒であった。アンテナ素子数 8 本 の場合と比べても, 計算時間に差異はないといえる。 さらに, 表 3 からもわかるように設定レベルとの誤差 は最大で $0.0045 \mathrm{~dB}$ となっている。アンテナ素子数が 増加しても実用時間内に妥当な解を得られている.

次に, 本論文におけるGAでは初期遺伝子, 突然変 異を共にランダムで発生させているため, 要求される 精度を持つ解に収束しない場合も生じる。そのため, GAに打ける収束安定性を明らかにするため, 同じ条 件で1000回行った。このとき, サイドローブ設定レ ベルとの最大許容誤差を $0.01 \mathrm{~dB} と し, G A$ 実行回数 に対して最大許容誤差以内の解を得られた割合を評価 
した。この割合を解の獲得率とし，(解の獲得率 $)=$ (解獲得回数) /(実行回数) とする.このときの解の獲 得率は $\mathrm{N}=10$ の場合， $81.8 \%, \mathrm{~N}=12$ の場合 $80.2 \%$ と

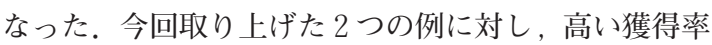
で高精度の解を得られた。この獲得率を改善するに は, パラメータの検討や実数值 $\mathrm{GA}$ や進化戦略を用い るといった応用的なGAの適用することが考えられる.

これまでの検証により， GAを適用することで逐次 法に比べて，処理コストが抑えられることが可能に なった。 また, 得られる解の精度は, 文献[8]に扔い てサイドローブレベルの最大誤差が $0.04 \mathrm{~dB}$ となって いる，GAを用いたとしても，高い確率で高精度(最大 誤差 $0.01 \mathrm{~dB}$ ) を有する解を獲得できると明らかになっ た。いずれにしても処理が少ない従来手法と比較すれ ば，処理コストはかかってしまうのが現状である。し かし, 実用時間内に精度の高い解を得られている点を 考慮すれば，提案手法は十分に有効である。また本論 文に打ける提案手法を用いれば，サイドローブのピー クレベルを制御するだけではなく, 最小值( ミニマム レベル)の制御も可能である。そのため, 従来手法で は実現不可能であった指向性制御が可能になると期待 できる。このような指向性の実現は, 今後の課題とし て挙げられる。

\section{7. まとめ}

本論文では，アレーアンテナのメインビームに対し て非対称の等サイドローブ指向性を得るためレベル制 御とサイドローブ制御を組み合わせる手法を提案し， 計算例を用いて本手法の有効性を示した。本手法で は，最適化法であるGAを計算過程において用い，計 算時間の短縮を図った。実用的には, 給電振幅および 移相量の制御にはデジタル減衰器打よびデジタル移相 器を用いることを想定している。提案した手法では, アレーアンテナ素子の給電振幅だけでなく移相量も同 時に制御することにより，メインビームに対して非対 称にビームを任意に制御可能になったことにより，多 種多様な指向性への応用が期待できる。その一例とし て，サイドローブレベルの設定值以上にするメイン ビームに対して非対称または対称の等ミニマム指向性 およびサイドローブが設定したレベル範囲内で振動す る等リップル指向性等への適用が考えられる.
参 考 文 献

[ 1 ] E.S.Elliott : Beamwidth and Directivity of Lsge Scanning Arrays," Forst of Two Parts, The Microwave Jounal, pp.53-60 (Dec., 1963).

[2] Keen-Keong Yan and Yilong Lu :"Sidelobe Reduction in Array-Pattern Systhesis Using Genetic Algorithm," IEEE Transections On Antennnas Propagation, 45, 7, pp.1117-1122 (July, 1997).

[ 3 ] T.B.Vu, B.E, Ph.D :"Method of Null Steering Without Using Phase Shifters," IEE Proceedings, 131, Pt.H, 4, pp.242-246, (Aug., 1984).

[ 4 ] C.L.Dolph, "A Current Distribution for Broad side Arrays Which Optimizes the Relationship between Beam Width and Side-Lobe Level," Ire Proc., 34, pp.335-348, (June, 1946).

[ 5 ] R. S. Elliott, "Design of line-source antennas for sum patterns with sidelobes of individually arbitrary heights," IEEE Trans. Antennas Propagat., vol. AP24, No.1, pp.76-83, (Jan., 1976).

[6] R. S. Elliott, "On discretizing continuous aperture distributions,” IEEE Trans. Antennas Propagat., vol. AP-25, No.5, pp.617-621, (Sept., 1977).

[ 7 ] H. J. Orchard, R. S. Elliott, and G. J. Stern, "Optimizing the synthesis of shaped beam antenna patterns," Proc. IEE, vol. 132, pt. H, No.1, pp.63-68, (Feb., 1985).

[ 8 ] R.S.Elliott,"Improved pattern synthesis for equispaced lineararrays," ALATAFREQUENZA,VOL.LI- N.6, pp.296-300, (Nov.-Dec., 1982).

[ 9 ] T.T.Tayor, "Design of line-source antenna for narrow beamwidth and low sidelobes," IRE Trans. Antennas Propagat, vol. AP-3, No.1,pp.16-28, (Jan., 1955) .

[10] D.E.Goldberg, "Genetic Algorithms in Search, Optimization, and Machine Learning." Addison Wesley, (1989).

(2009年 3 月 8 日 受付)

（2009年11月 4 日 採録）

[問い合わせ先］

于916-8507 福井県鯖江市下司町

福井工業高等専門学校

大久保 茂

TEL : 0778-62-8259

FAX : 0778-62-3413

E-mail :okubo@fukui-nct.ac.jp 


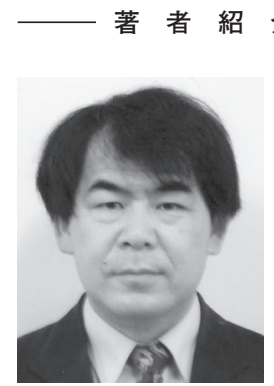

\section{大势势保 茂 $[$ 非会員 $]$}

1985年, 慶應義塾大学大学院工学 研究科博士課程修了。同年郵政省電波 研究所入所. 1989年, 福井工業高等 専門学校講師，2002年同教授，現在 に至る。アレーアンテナの指向性制御 および携帯電話を用いたWebアプリ ケーションの研究に従事. 工学博士.

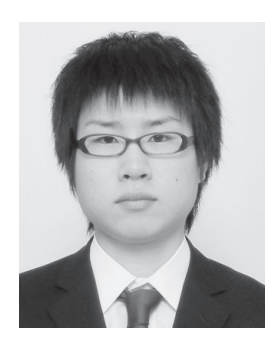

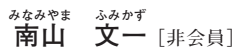

2009年, 福井工業高等専門学校専 攻科修了。同年名古屋大学大学院工学 研究科博士前期課程入学. 現在同大学 院在学中. 福井高専在学中はアレーア ンテナの指向性制御の研究に従事.

\title{
Controlling Asymmetric Equal Side Lobe Level in Radiation Patterns of Array Antenna using Genetic Algorithm \\ by
}

\section{Shigeru OKUBO and Fumikazu MINAMIYAMA}

\section{Abstract :}

Many studies have been reported on obtaining an asymmetric equal side lobe level in the radiation pattern of a linear array antenna. But they have the disadvantage that processes are complicated and the applications of them are limited. The new method for it is proposed in this paper. The method takes advantage of level controlling and side controlling. At the same time, the peak levels of the side lobe are controlled by level controlling and the levels in arbitrary directions in the radiation pattern are controlled by side lobe controlling. The amplitude and phase of the currents for an asymmetric equal side lobe level in the radiation pattern of a linear array antenna are calculated by the method. In order to save computing times to derive calculation results, Genetic Algorithm (GA) is adopted. The method is verified by the theoretical results. The process of the method is simple and we will be able to apply it to get various radiation patterns.

Keywords : Array antenna, Radiation patterns of asymmetric equal side lobe level, Genetic Algorithm, Level controlling, Side lobe controlling

\author{
Contact Address : Shigeru OKUBO \\ Fukui National College of Technology \\ Geshi-cho, Sabae city, Fukui, 916-8507, JAPAN \\ TEL :0778-62-8259 \\ FAX : 0778-62-3413 \\ E-mail : okubo@fukui-nct.ac.jp
}

